\title{
Challenges posed to the maternal circulation by pregnancy
}

This article was published in the following Dove Press journal:

Integrated Blood Pressure Control

29 August 2011

Number of times this article has been viewed

\section{Gloria Valdés \\ Jenny Corthorn}

Centro de Investigaciones

Médicas y Departamento

Nefrología, Escuela Medicina,

Pontificia Universidad Católica,

Santiago, Chile
Correspondence: Gloria Valdés

Centro de Investigaciones Médicas,

Escuela Medicina Pontificia Universidad

Católica, Marcoleta 39I, Santiago, Chile

$\mathrm{Tel}+5623548176$

Fax +5626321924

Email gvaldes@med.puc.cl
Abstract: In primates, adequate growth of the fetus depends on the development of the uteroplacental unit. On the fetal side, this is achieved by the creation of the vascular network of the placenta. On the maternal side, the transformation of the spiral arteries into saccular nonreactive vessels by the trophoblast provides high blood flow to the intervillous space. Apart from the changes in the uterine arteries, the mother expands her plasma volume - at the expense of stimulating the renin-angiotensin-aldosterone system - and her cardiac output. In the maintaining of normotension in the face of an increased cardiac output and plasma volume, the renin-angiotensin-aldosterone system requires an enhanced vasodilator synthesis. Finally, in the late stages of pregnancy, a normal endothelial function is required to provide an ample margin to the activation provoked by deportation of syncytiotrophoblast fragments/factors to the maternal circulation. These four adaptative processes require various interrelated vasodilator systems. Deficient adaptations cause isolated or proteinuric arterial hypertension, intrauterine growth restriction, preterm delivery, and stillbirths, among others. Moreover, a normal or a defective adaptation to pregnancy influences maternal cardiovascular health in later life, as evidenced by various studies, most of them epidemiological; thus, pregnancy is now considered a stress test to the maternal cardiovascular system. Because of this, women planning to become pregnant should be screened for clinical and biochemical cardiovascular risks. Inversely, women presenting with hypertension in pregnancy should be thoroughly studied to detect and correct cardiovascular risks. The incorporation of the predictive value of a hypertensive pregnancy should help reduce cardiovascular disease in women.

Keywords: renin-angiotensin-aldosterone system, prostanoids, kallikrein-kinin system, RAS, VEGF

\section{Introduction}

In primates, adequate growth of the fetus depends on the morphological and functional development of the uteroplacental unit. On the fetal side, this is achieved by the creation of the vascular network of the placenta from hemangioblasts. ${ }^{1}$ On the maternal side, this is achieved by (1) the transformation of the uterine arteries by extravillous trophoblasts that destroy their smooth muscle layer, change their tubular conformation into a saccular one, and make them nonreactive to vasomotor stimuli; 2,3 and (2) the elevation of the mother's plasma volume and cardiac output to bathe the placental villi with increasing fractions of the cardiac output. ${ }^{4,5}$

The expansion of plasma volume is due to the renin-angiotensin (Ang)-aldosterone system; plasma renin activity (PRA) and aldosterone levels increase progressively to attain values 7-8-fold higher than basal ones. In this context, the normotension of 
approximately $90 \%$ of pregnant women, the reduction of blood pressure in the second trimester, and the decreased sensitivity to endogenous Ang II infusion ${ }^{6}$ are difficult to understand, unless we invoke a potent vasodilatory response. The functional relevance of vasodilators to increase maternal vascular compliance in pregnancy is supported by the association of preeclampsia and intrauterine growth retardation to a reduced plasma volume that precedes the clinical expression of the syndrome. ${ }^{5,7}$ Moreover, in preeclampsia, PRA and Ang II levels are reduced, ${ }^{8}$ and the increase of vascular reactivity to Ang II contrasts with the decreased sensitivity observed in normal pregnancy. ${ }^{6}$

Convinced that an orchestrated network of vasodilator systems participates in the systemic and local changes of pregnancy, the authors of this paper have strived to understand their temporal profiles, localization, and potential roles. The following analysis will include a brief description of the main vasodilator agents/factors, the description of their systemic and local expression in human normal pregnancy and preeclampsia, and lastly an analysis of the implications of a defective adaptation over late cardiovascular morbimortality. (For a review that includes animal models, see Valdés et al. $)^{9}$

\section{Vasodilator factors and their systemic response in normotensive and preeclamptic pregnancy}

\section{Prostanoids}

Prostanoids are derived from arachidonic acid, which is mobilized from the cell membrane by phospholipase A2 and is metabolized by cyclooxygenases (COXs) (constitutive [COX-1] and inducible [COX-2]) into vasodilatory or vasoconstrictor prostaglandins (PGs) $\left(\mathrm{PGE}_{2} /\right.$ prostacyclin $\left[\mathrm{PGI}_{2}\right]$ and $\mathrm{PGF}_{2 \alpha}$ /thromboxane [TXA] respectively). $\mathrm{PGI}_{2}$, the main vasodilatory and antiaggregating $\mathrm{PG}$, is predominantly synthesized by the endothelium ${ }^{10}$ and represents the first vasoactive factor studied in this condition. ${ }^{11,12}$

For more than two decades, there has been evidence that the metabolites of $\mathrm{PGI}_{2}$ rise progressively to achieve a fivefold increment at term. Since this increment is not associated to increased TXA, the balance favors vasodilatation. ${ }^{11}$ Women with severe preeclampsia have a reduced excretion of $\mathrm{PGI}_{2}$ metabolites by weeks 13-16 of pregnancy, while TXA remains stable up to week 21 , to rise later causing a predominance of vasoconstriction and platelet aggregation. This imbalance could contribute to the main characteristics of preeclampsia, as hypertension, platelet aggregation, and reduced uteroplacental blood flow. Due to the disturbed $\mathrm{PGI}_{2} / \mathrm{TXA}$ balance several trials have tested low dose aspirin administration in women at risk of preeclampsia, with the intention of reducing synthesis of TXA in platelets, while that of endothelial $\mathrm{PGI}_{2}$ remains intact. However, the incidence of preeclampsia has only been reduced modestly (12\% in the Collaborative Low-dose Aspirin Study in Pregnancy $)^{13}$, suggesting that there is more to preeclampsia than an increment of TXA.

\section{Nitric oxide (NO)}

$\mathrm{NO}$, a potent vasodilator, is derived from the transformation of L-arginine into NO and citruline by NO synthase (NOS). The three cognate forms of NOS are the constitutive endothelial (eNOS) and neuronal (nNOS) forms, and the inducible (iNOS) form. ${ }^{14}$

In pregnant rats, NO synthesis increases, as demonstrated by plasma levels, urinary nitrites/nitrates, and cyclic guanosine monophosphate, second messenger of $\mathrm{NO} ;{ }^{15}$ moreover, the blockade of NO synthesis induces marked preeclampsialike effects. ${ }^{16,17}$ In human pregnancy, changes in the urinary excretion of nitrites/nitrates have been discordant, and this has been attributed to different content of these metabolites in the diet, and to a poor equivalence with NO production. However, elevated asymmetric dimethylarginine (ADMA), an endogenous inhibitor of NOS is associated to endothelial dysfunction, alterations of the uterine artery blood flow, and later development of preeclampsia. ${ }^{18}$

\section{Kallikrein-kinin system (KKS)}

The KKS system includes a couple of serine proteases: tissue and plasma kallikrein, which generate kallidin and bradykinin from low and high molecular kininogen respectively. The effects of kinins are mediated by bradykinin receptors (B1R and $\mathrm{B} 2 \mathrm{R}$ ), of which the $\mathrm{B} 2 \mathrm{R}$ induces vasodilatation and increased vascular permeability and platelet antiaggregation. ${ }^{19}$

The authors of this paper initially postulated that in pregnancy the KKS represented a counterpart to the vasoconstrictor renin-Ang system. However, the nadir attained by urinary kallikrein excretion in normal pregnancy between 8 and 12 weeks ${ }^{20}$ precedes the highest levels of vasoconstrictors. In hypertensive pregnancies, urinary kallikrein is reduced, and low values are a good predictor of preeclampsia. ${ }^{8,21,22}$

\section{Vasodilator components of the renin-Ang system (RAS)}

The RAS has traditionally been considered the paradigmatic vasoconstrictor system. ${ }^{23}$ More recently, various vasodilator 
pathways have been described within the RAS. One is represented by Ang-(1-7), the Mas receptor and the Ang converting enzyme-2 (ACE2); ${ }^{24}$ another by the stimulation of the receptor 2 of Ang II (AT-2-R) causes vasodilatation, antiproliferation, antifibrosis, and antiangiogenesis by activating eNOS and kinins, ${ }^{25-27}$ and lastly, by Ang-(3-8) or Ang IV, which provokes hypertrophy, vasodilatation, and vascular inflammation. ${ }^{28}$

Generation of Ang-(1-7) is increased in normotensive human gestation as demonstrated by increasing urinary excretion starting from 12 to 14 weeks, and by the elevation of plasma levels that result in late-pregnancy values 1.5 -fold greater than those of nonpregnant women. ${ }^{29,30}$ In preeclampsia, the circulating levels of Ang-(1-7) are reduced, a circulating agonistic antibody for the vasoconstrictor AT-1-R appears, ${ }^{31}$ and heterodimers of the AT-1-R-B2R receptors are increased in platelets and omental vessels; ${ }^{32}$ these heterodimers increase the vasoconstrictor effect of Ang II and reduce the vasodilatation of bradykinin. More recently, Zhou and collaborators have shown that oxidation of angiotensinogen, which has been observed in preeclampsia, renders this substrate more effective at liberating Ang by renin activity. ${ }^{33}$

\section{Vasodilator role of vascular endothelial growth factor (VEGF)}

VEGF, considered the most potent angiogenic stimulus, increases vascular permeability, cell migration, synthesis of metalloproteinases, and most importantly for this review, vasodilatation through $\mathrm{NO}$ and $\mathrm{PGI}_{2} \cdot{ }^{34-36}$ These effects are exerted through its receptors: VEGF receptor (VEGF-R)1 or fms-like tyrosine kinase (FLT)-1, and VEGF-R2 or kinase domain receptor (KDR). ${ }^{37,38}$

In women submitted to in-vitro fertilization, circulating levels of VEGF increase approximately 30 days after embryo transfer, ${ }^{39}$ and continue to increase up to weeks $34-36 .{ }^{40}$ Placental lobes liberate VEGF to the fetal and the maternal compartment, with a predominance to the latter. ${ }^{41}$

The binding of VEGF to its receptors is reduced by a soluble form (sFLT-1) generated by alternative splicing of FLT-1. The minimal circulating levels in the nonpregnant condition rise in pregnancy and are extremely elevated in preeclampsia, probably derived from the ischemic placenta. ${ }^{42,43}$ Mice transfected with the gene coding sFLT-1 present a preeclampsia-like syndrome in the absence of pregnancy. $^{42}$

The studies described above support the participation of several interrelated vasodilator systems in the maternal hemodynamic changes of pregnancy as a partially redundant network (Figure 1). It is highly likely that this network provides chained relay mechanisms in order to exert permanent vasodilatation along the changing hormonal milieu of pregnancy.

\section{Expression of vasodilator factors in the uteroplacental interface}

Since the vasodilator factors display paracrine/autocrine effects, their expression in reproductive human tissues is crucial to understand their participation in trophoblast invasion and in the development and maintenance of uteroplacental circulation.

\section{Prostanoids}

COX-1 is expressed in trophoblasts, endothelial cells, macrophages, smooth muscle, and decidual cells. COX-2 is expressed in macrophages, trophoblasts, fibroblasts, smooth muscle, and endothelial cells, and the expression of its mRNA does not differ between normal and preeclamptic pregnancies. The expression of COX-1 mRNA does not differ in placentas of normal or preeclamptic pregnancies, but is elevated in preeclampsia in the placental bed. ${ }^{44}$ The TXA/PGI 2 ratio, as well as that of lipid peroxides, is elevated in the cytotrophoblast and the stroma of placental villi. ${ }^{44}$ These results are in agreement with the first studies of prostanoids in human placenta, ${ }^{45}$ which indicate that the placenta, in particular the cytotrophoblast, contributes to the imbalance of the TXA/PGI ratio in preeclampsia, favoring platelet aggregation and the greater vascular reactivity of this condition.

\section{$\mathrm{NO}$}

In the first trimester, eNOS is expressed in syncytiotrophoblast, anchoring columns and the extravillous trophoblast. It is highly likely that NO liberated by the extravillous trophoblast primes the spiral arteries for their morphological transformation. ${ }^{46}$ This preconditioning is supported by the fact that in guinea pigs, only dilated arteries surrounded by trophoblasts expressing eNOS are subsequently invaded..$^{47}$

The expression of eNOS in human reproductive tissues in women with preeclampsia is discordant. However, the local and systemic improvement observed with L-arginine supplementation in hypertensive pregnant women (reduction of blood pressure, uterine artery resistance, synthesis of NO) supports the participation of NO in the systemic and local adaptation of pregnancy. ${ }^{48-51}$ In addition, in preeclampsia 


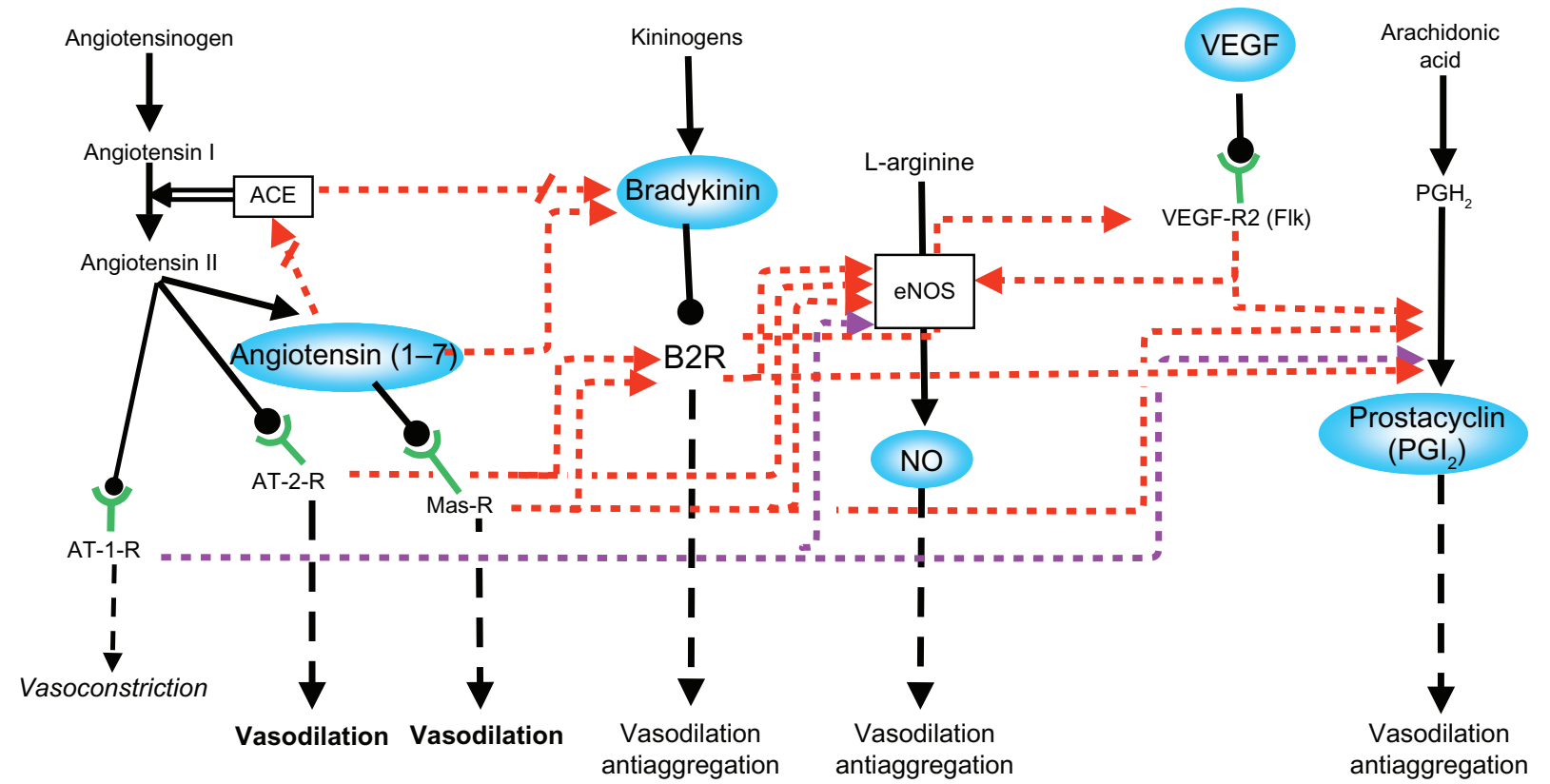

Figure I Interactions between the different vasodilator systems.

Note: Inhibitory pathways = arrows interrupted by oblique lines. Adapted from Valdés G, Kaufmann P, Corthorn J, Erices R, Brosnihan KB, Joyner-Grantham J. Vasodilator factors in the systemic and local adaptations to pregnancy. Reprod Biol Endocrinol. 2009;7:799 with permission of the publisher, BioMed Central.

Abbreviations: ACE, angiotensin converting enzyme; AT-I-R, angiotensin II type I receptor; AT-2-R, angiotensin II type 2 receptor; B2R, bradykinin 2 receptor; eNOS, endothelial nitric oxide synthase; Flk, fetal liver kinase I; Mas-R, Mas receptor; NO, nitric oxide; $\mathrm{PGH}_{2}$, prostaglandin $\mathrm{H}_{2}$; VEGF, vascular endothelial growth factor; VEGF-R2, VEGF receptor 2 .

the expression of placental arginase II - the enzyme that degrades arginine into ornithine - is elevated in placental villi, and the concentration of L-arginine is reduced in cord blood and in villi. ${ }^{52}$

\section{KKS}

The mRNAs that code for kallikrein and the $\mathrm{B} 2 \mathrm{R}$ are expressed in syncytiotrophoblast, cytotrophoblast, villous fetal endothelium, decidual cells of the basal and chorionic plate, and in intravascular and extravillous trophoblast. Kallikrein is present in these same cell types, with the exception of the anchoring columns and the extravillous trophoblast. ${ }^{53,54}$ In placenta accreta, a condition of exaggerated trophoblast invasion, the expression of kallikrein is increased in syncytiotrophoblast, and that of the B2R in the fetal endothelium and the extravillous trophoblast; in contrast to normal pregnancy, kallikrein is expressed in extravillous trophoblast. The only difference observed in preeclampsiathe increase of the B2R in the extravillous trophoblast - has been interpreted as support to the formation of AT-1-R and B2R heterodimers. ${ }^{55}$

The B2R-induced migration and invasion in immortalized extravillous trophoblasts recently described by the authors of this paper $^{56}$ supports the role of the KKS in placentation.

\section{Vasodilator components of the RAS}

The functional importance of the RAS in pregnancy is highlighted by the catastrophic effects of converting enzyme inhibitors on fetal wellbeing, ${ }^{57,58}$ by the association of preeclampsia to autoantibodies against the AT-1-R, and to the M235T polymorphism of the gene that codes for angiotensinogen, ${ }^{59}$ and finally, by the preeclamptic syndrome presented by female mice previously transfected with the human angiotensinogen mated with males transfected with the human renin gene. ${ }^{60}$ Ang-(1-7) and ACE2, its main generating enzyme, are expressed in syncytio and cytotrophoblast, villous smooth vascular muscle, extravillous and intraarterial trophoblast, decidual cells, umbilical cord endothelium, and vascular smooth muscle. Ang-(1-7) is no different in placental villi from normotensive and preeclamptic pregnancies, but Ang II is increased, suggesting a balance that favors vasoconstriction. ${ }^{61}$ In preeclamptic uterine placental bed, Ang II peptide levels, and renin- and Ang-converting enzyme mRNA expression were elevated compared with normal pregnancy. ${ }^{62}$ Angiotensinogen and the AT-1-R are increased in villi and decidua of preeclampsia. ${ }^{61}$ Herse et al found an overexpression of the vasoconstrictor AT-1-R mRNA in the decidua of preeclamptic pregnancies while that of the vasodilator AT-2-R in decidua and placenta was exceptionally present in preeclampsia and prevalent in control pregnancies. ${ }^{31}$ 
The expression of the vasodilator receptor of Ang IV, AT-4-R, is increased in normal term placentas and is reduced in preeclampsia. Placental explants incubated with Ang IV or Ang II show increased trophoblast invasion and reduced apoptosis. $^{63}$

\section{VEGF}

During the menstrual cycle, VEGF, and its receptors FLT-1 and KDR, are expressed in the endometrium. ${ }^{64,65}$ In pregnancy, VEGF is mainly expressed in villous cyto- and syncytiotrophoblast, the invading front of the anchoring columns, and extravillous and endovascular trophoblast. ${ }^{66-68}$ VEGF in the perivascular trophoblast could prime the spiral arteries to invasion, and in placental villi, enhance the blood flow in fetal capillaries. In a dual perfusion model of term placental lobes, physiological concentrations of VEGF exert a potent vasodilator effect on vascular fetoplacental vessels, partially mediated by KDR-induced NO stimulation. ${ }^{41}$ Transfection of the VEGF gene to uterine arteries provokes vasodilatation,

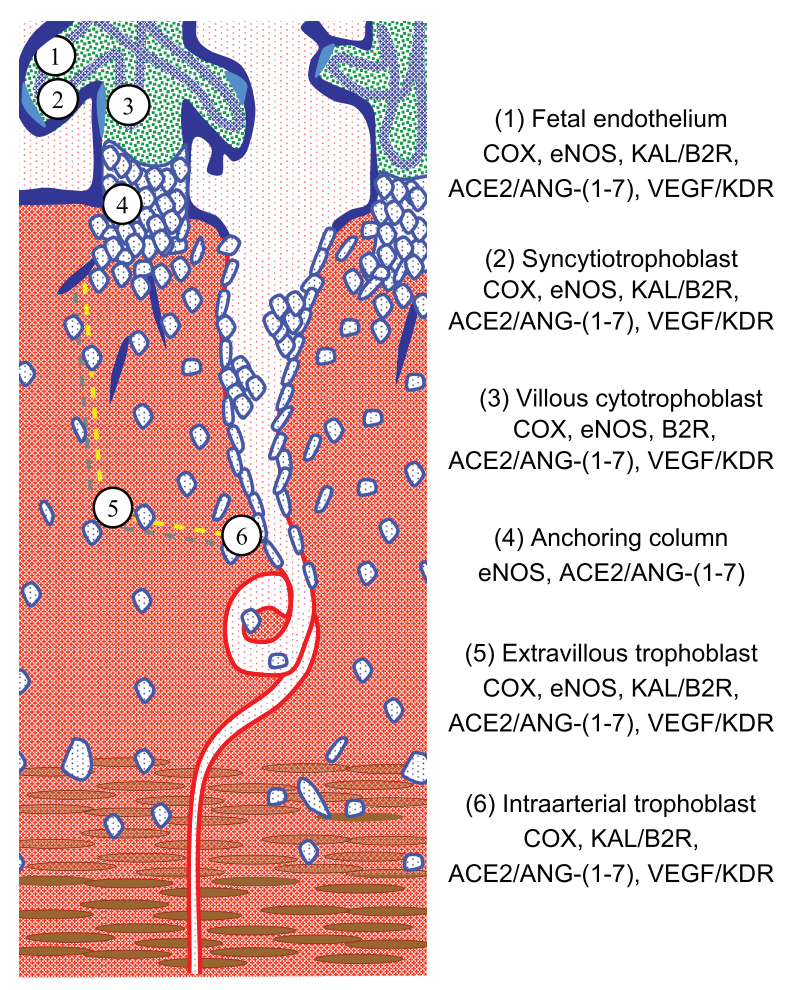

Figure 2 Diagram of the uteroplacental interface, showing its main cell types and the vasodilator repertoire of each type. ${ }^{9}$ The discontinuous yellow line depicts the path of trophoblasts that detach from the anchoring column to migrate through the uterine stroma, destroy the vascular smooth muscle, and colonize the lumen of the spiral arteries.

Note: Adapted from Valdés G, Kaufmann P, Corthorn J, Erices R, Brosnihan KB, Joyner-Grantham J. Vasodilator factors in the systemic and local adaptations to pregnancy. Reprod Biol Endocrinol. 2009;7:79 with permission of the publisher, BioMed Central.

Abbreviation: NK, natural killer. reduces the response to phenylephrine, and potentiates the response to bradykinin. ${ }^{69}$

The sites of expression of paracrine vasodilator factors, their generating enzymes, and their receptors (Figure 2) support their participation not only in blood flow regulation in fetal and maternal vessels but suggest other functions as well. Due to the cognate pleitropic effects of these factors, ${ }^{70}$ they could participate in platelet aggregation and in nonvasoactive processes such as: (1) angiogenesis, (2) interstitial trophoblast invasion, (3) transformation of spiral arteries, and (4) the replacement of their endothelium by intra-arterial trophoblast. However, it must be taken into account that the expression of vasodilator pleiotropic factors in late pregnancy does not represent their expression during the determinant first 20 weeks of pregnancy.

\section{Hypertensive pregnancy and its association with late cardiovascular disease in women}

Epidemiological studies associate preeclampsia, other hypertensive gestations, and diseases related to defective placentation to greater cardiovascular risk, ${ }^{71-75}$ so that pregnancy is considered a stress test to cardiovascular health. In addition, preeclampsia also increases the risk of end-stage renal disease. ${ }^{76}$

In a study performed by the authors of this paper, in women submitted to coronary angiography because of clinical suspicion of coronary artery disease, it was found that women with a previous hypertensive pregnancy presented a greater number of arteries with significant lesions according to age than women with normotensive gestation. ${ }^{77}$ This same study underscored the increased risk of a familial history of premature cardiovascular disease both for hypertension in pregnancy and coronary disease. Many are the risks shared by hypertensive pregnancy and cardiovascular disease (eg, obesity, metabolic syndrome, diabetes, premature cardiovascular disease, endothelial dysfunction, thrombophilias, hyperhomocistinemia, inflammation, ADMA, and oxidative stress). These factors provoke the first stage of atheromatous disease, endothelial dysfunction, which has been demonstrated far from parturition in subjects with prior preeclampsia, ${ }^{18}$ and especially with early onset preeclampsia. ${ }^{78}$ As women with recurrent miscarriages also present endothelial dysfunction, ${ }^{79}$ this alteration probably lies at the root of placentation defects and is not derived from the hypertensive phase of preeclampsia. It is feasible that the association between hypertensive pregnancies and 
late cardiovascular disease is given by risk factors within high normal limits in the reproductive stage, which do not provide an ample margin to the metabolic, hemodynamic, and inflammatory changes provoked by gestation. Based on the hypothesis that hypertension in pregnancy expresses a combination of underlying maternal conditions, and the placental debris/factors that are shed into the maternal circulation, the authors of this paper propose that proteinuric hypertension (preeclampsia) derives from combinations of placental and preexisting maternal factors (Figure 3). Nonproteinuric hypertension (eg, transient hypertension or exacerbation of a preexistent hypertension) on the contrary may derive from a reduced capacity to stimulate vasodilator/ antiaggregating factors (eg, $\mathrm{PGI}_{2}$, kallikrein, and Ang-(1-7)), a limitation that impinges the maternal hemodynamic adaptation to pregnancy, and later favors the development of cardiovascular disease.

The authors of this paper cannot avoid referring to the lasting hemodynamic and metabolic effects exerted on the offspring by severe reduced perfusion of the intervillous space either in intrauterine or later life (alterations in the fetal arteries in order to preserve cerebral blood flow, intrauterine growth restriction, oligamnion, and spontaneous or induced preterm delivery). Be it by genetic determinants of trophoblast invasion, vasoactive adaptation, epigenetic changes, or intrauterine programming, the offspring will have a higher cardiovascular and metabolic risk, ${ }^{80,81}$ which needs to be addressed.

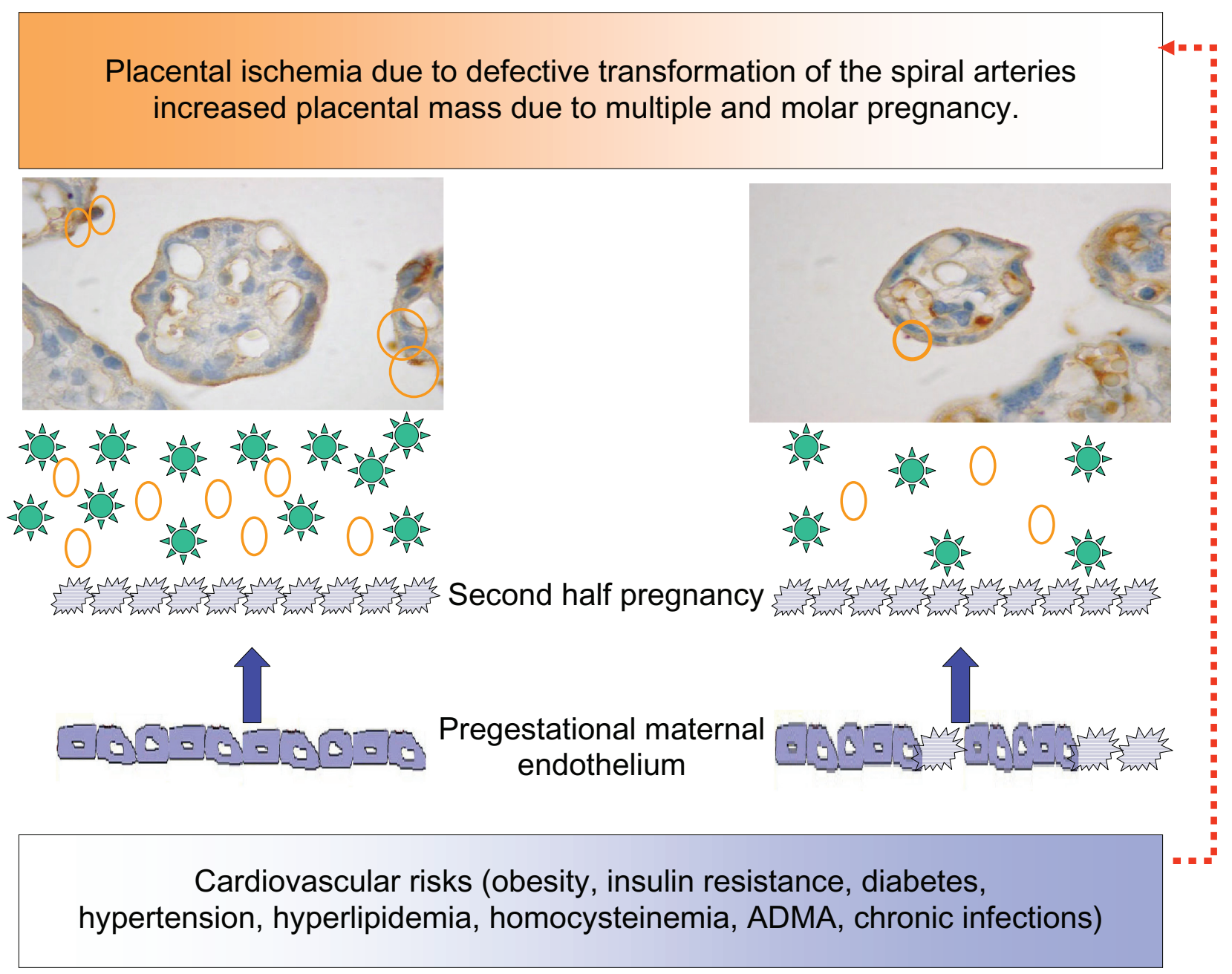

Figure 3 Diagram showing the relation between the placenta and the maternal endothelium, in ischemic conditions, increased placental mass, and underlying cardiovascular risks. The microphotographs of the placental villi show syncytial knots prior to being deported into the maternal circulation (orange circles). In addition, the placenta sheds factors to the maternal circulation (green stars: sFLT-I, agonist autoantibodies to the AT-I-R, ADMA, and reactive oxygen species). Both syncytiotrophoblast microparticles and the soluble factors provoke endothelial dysfunction in pregestational healthy (smooth borders) or dysfunctional endothelial cells (spiky borders). Pregestational endothelial dysfunction also hinders uterine artery transformation (red broken arrow).

Abbreviations: ADMA, asymmetric dimethylarginine; AT-I-R, angiotensin II type I receptor; sFLT-I, soluble fms-like tyrosine kinase I. 


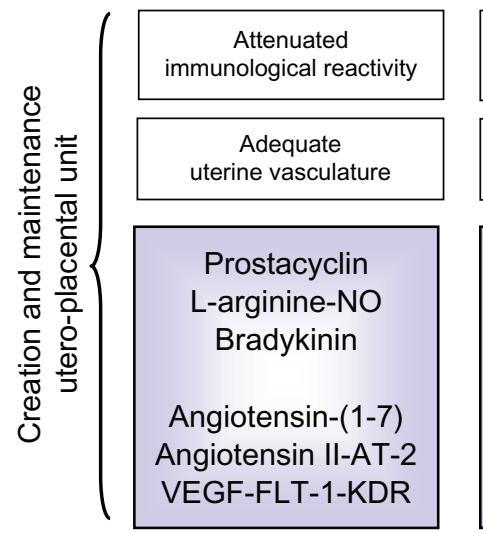

Exacerbated immunological reactivity

Immature or damaged uterine vasculature

Thromboxane ADMA, arginase II B2R-AT-1-R dimers Agonist antibody AT-1-R Angiotensin II-AT-1 VEGF-sFLT-1

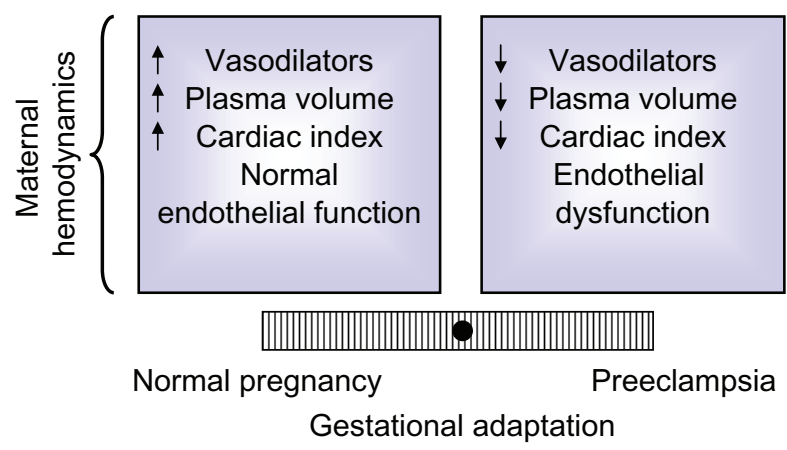

Figure 4 Balance of factors that determine an adequate or defective adaptation to pregnancy in the maternal hemodynamics and in the development and maintenance of the uteroplacental unit, ${ }^{9}$ based on the equilibrium initially proposed for $\mathrm{PGI}_{2}$ and TXA ${ }^{45}$ The modulation of the maternal immune reaction and the state of the maternal vasculature have also been included, because though not analyzed in this review, they influence the adaptation to pregnancy.

Note: Adapted from Valdés G, Kaufmann P, Corthorn J, Erices R, Brosnihan KB, JoynerGrantham J. Vasodilator factors in the systemic and local adaptations to pregnancy. Reprod Biol Endocrinol. 2009;7:79 with permission of the publisher, BioMed Central.

Abbreviations: ADMA, asymmetric dimethylarginine; AT-I-R, angiotensin II type I receptor; AT-I, angiotensin II type I; AT-2, angiotensin II type 2; B2R, bradykinin 2 receptor; KDR, kinase domain receptor; FLT-I, fms-like tyrosine kinase I; NO, nitric oxide; sFLT-I, soluble fms-like tyrosine kinase I;VEGF, vascular endothelial growth factor

\section{Conclusion}

The data analyzed in this review shows that normal gestation represents a paradigm of a finely tuned vasodilator/vasoconstrictor balance, which is tipped to the vasoconstrictor arm, in preeclampsia (Figure 4). On the other hand, the multiple factors that determine an adequate systemic and local adaptation also provide a diversity of pathways that could go awry and generate preeclampsia, transforming what was initially considered a disease into a syndrome.

Having focused on the equilibrium of vasoactive systems, we cannot disregard the morphological changes of the cardiovascular system induced by gestation. The high flow arteriovenous fistula represented by the intervillous space, and the increases in aortic valve area, ventricular mass, ${ }^{82}$ and aortic compliance ${ }^{83}$ underscore the extraordinary cardiovascular plasticity demanded by pregnancy.
The authors of this paper wish to emphasize that an adequate or a defective adaptation to pregnancy is expressed in several stages. The first silent stage is determined by an extensive or a shallow trophoblast invasion, and is only detected by ultrasonographic study of uterine arteries. The second is expressed clinically as a normal, preeclamptic, or a hypertensive pregnancy depending on the amount of placental deportation and the conditions of the maternal vasculature. Lastly, when the protection provided by estrogen is lost, cardiovascular diseases will be absent or present depending on the underlying risks that influenced pregnancy and the variations induced by lifestyle. No wonder gestation, which is equivalent to a prolonged moderate exercise, ${ }^{82}$ is a powerful and lasting stress test. ${ }^{84}$

\section{Acknowledgments}

The studies of the vasodilator factors have been supported by Fondo Nacional de Ciencia y Tecnología, Chile (Grants 1940636, 1980958, 1020705, 1050707, and 1080228).

\section{Disclosure}

The authors have no conflicts of interest to report in relation to this paper.

\section{References}

1. Charnock-Jones DS, Kaufmann P, Mayhew TM. Aspects of human fetoplacental vasculogenesis and angiogenesis. I. Molecular regulation. Placenta. 2004;25:103-113.

2. Kaufmann P, Black S, Huppertz B. Endovascular trophoblast invasion: implications for the pathogenesis of intrauterine growth retardation and preeclampsia. Biol Reprod. 2003;69:1-7.

3. Red-Horse K, Zhou Y, Genbacev O, et al. Trophoblast differentiation during embryo implantation and formation of the maternal-fetal interface. J Clin Invest. 2004;114:744-754.

4. Hytten F. Blood volume changes in normal pregnancy. Clin Haematol. 1985;14:601-612.

5. Salas SP, Rosso P, Espinoza R, Robert JA, Valdés G, Donoso E. Maternal plasma volume expansion and hormonal changes in women with idiopathic fetal growth retardation. Obstet Gynecol. 1993;81:1029-1033.

6. Gant NF, Daley GL, Chand S, Whalley PJ, MacDonald PC. A study of angiotensin II pressor response throughout primigravid pregnancy. J Clin Invest. 1973;52:2682-2689.

7. Salas SP, Marshall G, Gutierrez BL, Rosso P. Time course of maternal plasma volume and hormonal changes in women with preeclampsia or fetal growth restriction. Hypertension. 2006;47:203-208.

8. Karlberg BE, Rydén G, Wichman K. Changes in the renin-angiotensinaldosterone and kallikrein-kinin systems during normal and hypertensive pregnancy. Acta Obstet Gynecol Scand. 1984;118:17-24.

9. Valdés G, Kaufmann P, Corthorn J, Erices R, Brosnihan KB, JoynerGrantham J. Vasodilator factors in the systemic and local adaptations to pregnancy. Reprod Biol Endocrinol. 2009;7:79.

10. Gryglewski RJ. Prostacyclin among prostanoids. Pharmacol Rep. 2008;60:3-11.

11. Bussolino F, Benedetto C, Massobrio M, Camussi G. Maternal vascular prostacyclin activity in pre-eclampsia. Lancet. 1980;2:702.

12. Ylikorkala O, Pekonen F, Viinikka L. Renal prostacyclin and thromboxane in normotensive and preeclamptic pregnant women and their infants. J Clin Endocrinol Metab. 1986;63:1307-1312. 
13. CLASP: a randomised trial of low-dose aspirin for the prevention and treatment of pre-eclampsia among 9364 pregnant women. CLASP (Collaborative Low-dose Aspirin Study in Pregnancy) Collaborative Group. Lancet. 1994;343:619-629.

14. Knowles RG, Moncada S. Nitric oxide synthases in mammals. Biochem J. 1994;298:249-258.

15. Conrad KP, Joffe GM, Kruszyna H, et al. Identification of increased nitric oxide biosynthesis during pregnancy in rats. FASEB J. 1993;7:566-571.

16. Molnar M, Suto T, Toth T, Hertelendy F. Prolonged blockade of nitric oxide synthesis in gravid rats produces sustained hypertension, proteinuria, thrombocytopenia, and intrauterine growth retardation. Am J Obstet Gynecol. 1994;170:1458-1466.

17. Yallampalli C, Garfield RE. Inhibition of nitric oxide synthesis in rats during pregnancy produces signs similar to those of preeclampsia. $\mathrm{Am}$ J Obstet Gynecol. 1993;169:1316-1320.

18. Savvidou MD, Hingorani AD, Tsikas D, Frolich JC, Vallance P, Nicolaides KH. Endothelial dysfunction and raised plasma concentrations of asymmetric dimethylarginine in pregnant women who subsequently develop pre-eclampsia. Lancet. 2003;361:1511-1517.

19. Moreau ME, Garbacki N, Molinaro G, Brown NJ, Marceau F, Adam A. The kallikrein-kinin system: current and future pharmacological targets. J Pharmacol Sci. 2005;99:6-38.

20. Valdés G, Foradori A, Oyarzún E, et al. Urinary kallikrein along cycle, pregnancy and lactation. Prenatal Neonatal Medicine. 1998;3:474-481.

21. Elebute OA, Mills IH. Urinary kallikrein in normal and hypertensive pregnancies. Perspect Nephrol Hypertens. 1976;5:329-338.

22. Kyle PM, Campbell S, Buckley D, et al. A comparison of the inactive urinary kallikrein:creatinine ratio and the angiotensin sensitivity test for the prediction of pre-eclampsia. Br J Obstet Gynaecol. 1996;103:981-987.

23. Fyhrquist F, Saijonmaa O. Renin-angiotensin system revisited. J Intern Med. 2008;264:224-236.

24. Ferrario CM, Brosnihan KB, Diz DI, et al. Angiotensin-(1-7): a new hormone of the angiotensin system. Hypertension. 1991;18(5 Suppl):III126-III133.

25. Tsutsumi Y, Matsubara H, Masaki H, et al. Angiotensin II type 2 receptor overexpression activates the vascular kinin system and causes vasodilation. J Clin Invest. 1999;104:925-935.

26. Widdop RE, Matrougui K, Levy BI, Henrion D. AT2 receptor-mediated relaxation is preserved after long-term AT1 receptor blockade. Hypertension. 2002;40:516-520.

27. Yayama K, Hiyoshi H, Imazu D, Okamoto H. Angiotensin II stimulates endothelial NO synthase phosphorylation in thoracic aorta of mice with abdominal aortic banding via type 2 receptor. Hypertension. 2006;48:958-964.

28. Coleman JK, Krebs LT, Hamilton TA, et al. Autoradiographic identification of kidney angiotensin IV binding sites and angiotensin IVinduced renal cortical blood flow changes in rats. Peptides. 1998;19: 269-277.

29. Merrill DC, Karoly M, Chen K, Ferrario CM, Brosnihan KB. Angiotensin-(1-7) in normal and preeclamptic pregnancy. Endocrine. 2002;18:239-245

30. Valdés G, Germain AM, Corthorn J, et al. Urinary vasodilator and vasoconstrictor angiotensins during menstrual cycle, pregnancy, and lactation. Endocrine. 2001;16:117-122.

31. Herse F, Dechend R, Harsem NK, et al. Dysregulation of the circulating and tissue-based renin-angiotensin system in preeclampsia. Hypertension. 2007;49:604-611.

32. AbdAlla S, Lother H, el Massiery A, Quitterer U. Increased AT(1) receptor heterodimers in preeclampsia mediate enhanced angiotensin II responsiveness. Nat Med. 2001;7:1003-1009.

33. Zhou A, Carrell RW, Murphy MP, et al. A redox switch in angiotensinogen modulates angiotensin release. Nature. 2010;468:108-111.

34. Dvorak HF, Brown LF, Detmar M, Dvorak AM. Vascular permeability factor/vascular endothelial growth factor, microvascular hyperpermeability, and angiogenesis. Am J Pathol. 1995;146:1029-1039.
35. Brownbill P, Mills TA, Soydemir DF, Sibley CP. Vasoactivity to and endogenous release of vascular endothelial growth factor in the in vitro perfused human placental lobule from pregnancies complicated by preeclampsia. Placenta. 2008;29:950-955.

36. Wheeler-Jones C, Abu-Ghazaleh R, Cospedal R, Houliston RA, Martin J, Zachary I. Vascular endothelial growth factor stimulates prostacyclin production and activation of cytosolic phospholipase A2 in endothelial cells via p42/p44 mitogen-activated protein kinase. FEBS Lett. 1997;420:28-32.

37. Tammela T, Enholm B, Alitalo K, Paavonen K. The biology of vascular endothelial growth factors. Cardiovasc Res. 2005;65:550-563.

38. Olsson AK, Dimberg A, Kreuger J, Claesson-Welsh L. VEGF receptor signalling - in control of vascular function. Nat Rev Mol Cell Biol. 2006;7:359-371.

39. Evans PW, Wheeler T, Anthony FW, Osmond C. A longitudinal study of maternal serum vascular endothelial growth factor in early pregnancy. Hum Reprod. 1998;13:1057-1062.

40. Bosio PM, Wheeler T, Anthony F, Conroy R, O'Herlihy C, McKenna P. Maternal plasma vascular endothelial growth factor concentrations in normal and hypertensive pregnancies and their relationship to peripheral vascular resistance. Am J Obstet Gynecol. 2001;184: 146-152.

41. Brownbill P, McKeeman GC, Brockelsby JC, Crocker IP, Sibley CP. Vasoactive and permeability effects of vascular endothelial growth factor-165 in the term in vitro dually perfused human placental lobule. Endocrinology. 2007;148:4734-4744.

42. Maynard SE, Min JY, Merchan J, et al. Excess placental soluble fms-like tyrosine kinase 1 (sFlt1) may contribute to endothelial dysfunction, hypertension, and proteinuria in preeclampsia. J Clin Invest. 2003;111:649-658.

43. Levine RJ, Qian C, Maynard SE, Yu KF, Epstein FH, Karumanchi SA. Serum sFlt1 concentration during preeclampsia and mid trimester blood pressure in healthy nulliparous women. Am J Obstet Gynecol. 2006;194:1034-1041.

44. Wetzka B, Nusing R, Charnock-Jones DS, Schafer W, Zahradnik HP, Smith SK. Cyclooxygenase-1 and -2 in human placenta and placental bed after normal and pre-eclamptic pregnancies. Hum Reprod. 1997; 12:2313-2320.

45. Walsh SW. Preeclampsia: an imbalance in placental prostacyclin and thromboxane production. Am J Obstet Gynecol 1985;152: 335-340.

46. Craven CM, Morgan T, Ward K. Decidual spiral artery remodelling begins before cellular interaction with cytotrophoblasts. Placenta. 1998;19:241-252.

47. Nanaev A, Chwalisz K, Frank HG, Kohnen G, Hegele-Hartung C, Kaufmann P. Physiological dilation of uteroplacental arteries in the guinea pig depends on nitric oxide synthase activity of extravillous trophoblast. Cell Tissue Res. 1995;282:407-421.

48. Facchinetti F, Longo M, Piccinini F, Neri I, Volpe A. L-arginine infusion reduces blood pressure in preeclamptic women through nitric oxide release. J Soc Gynecol Investig. 1999;6:202-207.

49. Facchinetti F, Saade GR, Neri I, Pizzi C, Longo M, Volpe A. L-arginine supplementation in patients with gestational hypertension: a pilot study. Hypertens Pregnancy. 2007;26:121-130.

50. Germain AM, Valdés G, Romanik MC, Reyes MS. Evidence supporting a beneficial role for long-term L-arginine supplementation in high-risk pregnancies. Hypertension. 2004;44:e1.

51. Neri I, Jasonni VM, Gori GF, Blasi I, Facchinetti F. Effect of L-arginine on blood pressure in pregnancy-induced hypertension: a randomized placebo-controlled trial. J Matern Fetal Neonatal Med. 2006;19:277-281.

52. Noris M, Todeschini M, Cassis P, et al. L-arginine depletion in preeclampsia orients nitric oxide synthase toward oxidant species. Hypertension. 2004;43:614-622.

53. Valdés G, Chacón C, Corthorn J, Figueroa CD, Germain AM. Tissue kallikrein in human placenta in early and late gestation. Endocrine. 2001;14:197-204. 
54. Valdés G, Germain AM, Corthorn J, Chacón C, Figueroa CD, Muller-Esterl W. Tissue kallikrein and bradykinin B2 receptor in human uterus in luteal phase and in early and late gestation. Endocrine. 2001;16:207-215.

55. Furuya M, Kurasawa K, Nagahama K, et al. Disrupted balance of angiogenic and antiangiogenic signalings in preeclampsia. J Pregnancy. 2011;2011:123717.

56. Erices R, Corthorn J, Lisboa F, Valdés G. Bradykinin promotes migration and invasion of human immortalized trophoblasts. Reprod Biol Endocrinol. 2011;9:97.

57. Kreft-Jais C, Plouin PF, Tchobroutsky C, Boutroy MJ. Angiotensinconverting enzyme inhibitors during pregnancy: a survey of 22 patients given captopril and nine given enalapril. Br J Obstet Gynaecol. 1988;95:420-422.

58. Hanssens M, Keirse MJ, Vankelecom F, Van Assche FA. Fetal and neonatal effects of treatment with angiotensin-converting enzyme inhibitors in pregnancy. Obstet Gynecol. 1991;78:128-135.

59. Inoue I, Rohrwasser A, Helin C, et al. A mutation of angiotensinogen in a patient with preeclampsia leads to altered kinetics of the renin-angiotensin system. J Biol Chem. 1995;270: 11430-11436.

60. Takimoto E, Ishida J, Sugiyama F, Horiguchi H, Murakami K, Fukamizu A. Hypertension induced in pregnant mice by placental renin and maternal angiotensinogen. Science. 1996;274:995-998.

61. Anton L, Merrill DC, Neves LA, et al. Activation of local chorionic villi angiotensin II levels but not angiotensin (1-7) in preeclampsia. Hypertension. 2008;51:1066-1072.

62. Anton L, Merrill DC, Neves LA, et al. The uterine placental bed renin-angiotensin system in normal and preeclamptic pregnancy. Endocrinology. 2009;150:4316-4325.

63. Williams PJ, Mistry HD, Innes BA, Bulmer JN, Pipkin FB. Expression of AT1R, AT2R and AT4R and their roles in extravillous trophoblast invasion in the human. Placenta. 31:448-455.

64. Krussel JS, Casan EM, Raga F, et al. Expression of mRNA for vascular endothelial growth factor transmembraneous receptors Flt1 and KDR, and the soluble receptor sflt in cycling human endometrium. Mol Hum Reprod. 1999;5:452-458.

65. Moller B, Lindblom B, Olovsson M. Expression of the vascular endothelial growth factors B and $\mathrm{C}$ and their receptors in human endometrium during the menstrual cycle. Acta Obstet Gynecol Scand. 2002;81:817-824.

66. Demir R, Kayisli UA, Seval Y, et al. Sequential expression of VEGF and its receptors in human placental villi during very early pregnancy: differences between placental vasculogenesis and angiogenesis. Placenta. 2004;25:560-572.

67. Campbell S, Rowe J, Jackson CJ, Gallery ED. Interaction of cocultured decidual endothelial cells and cytotrophoblasts in preeclampsia. Biol Reprod. 2004;71:244-252.
68. Shiraishi S, Nakagawa K, Kinukawa N, Nakano H, Sueishi K Immunohistochemical localization of vascular endothelial growth factor in the human placenta. Placenta. 1996;17:111-121.

69. David AL, Torondel B, Zachary I, et al. Local delivery of VEGF adenovirus to the uterine artery increases vasorelaxation and uterine blood flow in the pregnant sheep. Gene Ther. 2008;15:1344-1350.

70. Valdés G, Corthorn J. Review: the angiogenic and vasodilatory uteroplacental network. Placenta. 2011;32 Suppl 2:S170-S175.

71. Bellamy L, Casas JP, Hingorani AD, Williams DJ. Pre-eclampsia and risk of cardiovascular disease and cancer in later life: systematic review and meta-analysis. BMJ. 2007;335:974.

72. Craici IM, Wagner SJ, Hayman SR, Garovic VD. Pre-eclamptic pregnancies: an opportunity to identify women at risk for future cardiovascular disease. Womens Health. 2008;4:133-135.

73. Smith GC, Pell JP, Walsh D. Pregnancy complications and maternal risk of ischaemic heart disease: a retrospective cohort study of 129, 290 births. Lancet. 2001;357:2002-2006.

74. Wilson BJ, Watson MS, Prescott GJ, et al. Hypertensive diseases of pregnancy and risk of hypertension and stroke in later life: results from cohort study. BMJ. 2003;326:845.

75. Irgens HU, Reisaeter L, Irgens LM, Lie RT. Long term mortality of mothers and fathers after pre-eclampsia: population based cohort study. BMJ. 2001;323:1213-1217.

76. Vikse BE, Irgens LM, Leivestad T, Skjaerven R, Iversen BM. Preeclampsia and the risk of end-stage renal disease. $N$ Engl J Med. 2008;359:800-809.

77. Valdés G, Quezada F, Marchant E, et al. Association of remote hypertension in pregnancy with coronary artery disease: a case-control study. Hypertension. 2009;53:733-738.

78. Yinon Y, Kingdom JC, Odutayo A, et al. Vascular dysfunction in women with a history of preeclampsia and intrauterine growth restriction insights into future vascular risk. Circulation. 2010;122:1846-1853.

79. Germain AM, Romanik MC, Guerra I, at al. Endothelial dysfunction: a link among preeclampsia, recurrent pregnancy loss, and future cardiovascular events? Hypertension. 2007;49:90-95.

80. Barker DJ. The developmental origins of adult disease. J Am Coll Nutr. 2004;23(6 Suppl):588S-595S.

81. Gluckman PD, Hanson MA, Cooper C, Thornburg KL. Effect of in utero and early-life conditions on adult health and disease. $N$ Engl J Med. 2008;359:61-73.

82. Robson SC, Hunter S, Boys RJ, Dunlop W. Serial study of factors influencing changes in cardiac output during human pregnancy. Am J Physiol. 1989;256:H1060-H1065.

83. Poppas A, Shroff SG, Korcarz CE, et al. Serial assessment of the cardiovascular system in normal pregnancy. Role of arterial compliance and pulsatile arterial load. Circulation. 1997;95:2407-2415.

84. Williams D. Pregnancy: a stress test for life. Curr Opin Obstet Gynecol. $2003 ; 15: 465-471$
Integrated Blood Pressure Control

\section{Publish your work in this journal}

Integrated Blood Pressure Control is an international, peer-reviewed open-access journal focusing on the integrated approach to managing hypertension and risk reduction. Treating the patient and comorbidities together with diet and lifestyle modification and optimizing healthcare resources through a multidisciplinary team approach constitute key

\section{Dovepress}

features of the journal. This journal is indexed on American Chemical Society's Chemical Abstracts Service (CAS). The manuscript management system is completely online and includes a very quick and fair peerreview system, which is all easy to use. Visit http://www.dovepress.com/ testimonials.php to read real quotes from published authors. 